\title{
Maternal Health, Social Conservatism and Hypocrisy: Canadian Edition
}

\author{
Masood Zangeneh
}

Published online: 5 June 2010

(C) Springer Science+Business Media, LLC 2010

Recent policy and funding announcements by the Canadian Conservative government regarding abortion has stunned many local and international spectators. This Conservative government has announced that its international aid package to the poor and developing countries will no longer cover the cost of legal abortion. At present, Canada's decision only affects a small number of developing countries that have legalized abortion as a standard medical practice. However this should be taken as a grim warning and indication that Canada will be moving in the direction of excluding abortion from future aid packages to all poor and developing countries.

Why do Canadians need to financially assist those who need or may need abortion services in poor and developing countries?

The position I wish to take on this issue is concern for victims of rape who are forced to use shady, medically questionable and dangerous backroom practices to abort their unwanted, forced pregnancy when they cannot afford covering the expenses at legal and safe medical facilities.

Globally, sexual violence is a vicious reality. This horrific act is even more pronounced in conflict zones where rape is consistently used as a weapon of war (e.g. Rwandan genocide). This victimization is further exacerbated when the victims are denied of justice due to gender discrimination or even worse when they are denied of basic sound and safe medical care to deal with this brutal assault and its damaging outcomes such as an unwanted pregnancy.

Dangerous and unsafe abortion is recognized as one of the major health problems in poor and developing countries where it is typically practiced in an unregulated, unsanitary environment. Under these circumstances, abortion service providers are usually untrained and unqualified where they put women's life at risk of various medical complications (e.g. sepsis, anemia, cervical tear, pelvic abscess uterine perforation with peritonitis, chemical vaginitis and other genital and abdominal trauma), even death (AbouZahr 1998.)

Current literature clearly necessitates an urgent attention to this major global catastrophe and justifiably we should view this task as a moral imperative that first world countries, 
especially those who are the helm of the G8/G20 group, make this matter a priority and guarantee continued financial support to ensure that the most marginalized groups (e.g. female victims of rape) in the most vulnerable countries have access to the most basic human needs.

A recent editorial by the Lancet (2010) was correct to highlight Conservative Government's hypocrisy, however if history has taught us anything it is the fact that the conservative government of Canada has taken this ingenious yet malicious strategy to pave a way their own agenda in reversing progressive policy of legal abortion in Canada. The Conservative government may look as a hypocrite today while cutting funding for abortion to the developing countries and allowing legal abortion in Canada. However, its goal is to be consistent eventually by getting rid of abortion rights for women in Canada as well as abroad, a policy that fits well with social conservative ideology.

So after all, Canada's new policy and funding stand is about conservative ideology and moral agenda.

As I write this editorial, efforts are underway to host the upcoming G20 summit in Toronto, Canada. It is more fitting to rightly view this as the moral and social responsibility of the G8/G20 group to demand that Canada adheres to their international and humanitarian obligation and force it to join the agreement to include the basic human rights necessities (including rights to access to medically sound and safe abortion) for the most vulnerable members of all poor and developing nations.

We hope that social and political agendas are not considered at the expense of the poor and most vulnerable pregnant women in the poorest part of the world.

\section{References}

AbouZahr, C. (1998). Puerperal sepsis and other puerperal infections. In C. J. L. Murray \& A. D. Lopez (Eds.), Health dimensions of sex and reproduction. Boston: Harvard School of Public Health.

Editorial. (2010). Canada's G8 health leadership. The Lancet, 375(9726), 1580. doi:10.1016/S0140-6736(08) $61345-8$ 